\title{
On one Approach to Control the Dynamic Properties of a Cylindrical Piezoceramic Acoustoelectronic Device with Single-frequency Resonant Excitation
}

\author{
O.H. Leiko*, N.V. Bogdanova, O.V. Bogdanov, A.O. Leiko, O.V. Harmash \\ National Technical University of Ukraine \\ "Igor Sikorsky Kyiv Polytechnic Institute", 16, Politekhnichna St., 03056 Kyiv, Ukraine
}

(Received 02 December 2020; revised manuscript received 15 April 2021; published online 20 April 2021)

\begin{abstract}
Potentially achievable dynamic properties of an acoustoelectronic device with single-frequency resonant excitation in the form of a coaxial system formed from two cylindrical piezoceramic shells and a liquid layer between them, depending on the physical characteristics of this liquid, are investigated. By the method of numerical analysis, on the example of acoustic fields, the peculiarities of the behavior of potentially possible dynamic properties of such devices for the options of their construction with filling with liquids with different density and speed of sound in them are established. The peculiarities of the influence of the physical characteristics of the liquids that fill the device on the potentially possible dynamic properties of acoustoelectronic devices of this type are studied. It is shown that these features consist in the formation of two resonance regions, which differ significantly in the central frequencies, the resonant frequency bands and the maximum pressure amplitudes in them. Filling devices with light liquids causes a decrease in the values of the central frequency of the resonance regions and the frequency interval of small pressure amplitudes between the two resonance regions. Filling devices with heavy liquids is characterized by the opposite effect. The influence on the established potentially possible dynamic properties of such devices is analyzed by introducing operational control methods into them from the electrical side. The physical reasons for the emergence of the established dynamic properties are stated.
\end{abstract}

Keywords: Acoustoelectronic device, Single frequency resonant excitation, Potential dynamic properties, Filling fluids.

DOI: $10.21272 /$ jnep.13(2).02028

PACS number: 77.65.Dq

\section{INTRODUCTION}

Acoustoelectronic devices with dynamic control of their parameters are widely used in modern technical means of acoustic sounding of sea space [1-4]. One of the variants for constructing such an acoustoelectronic device is described in papers $[3,5]$. It represents (see Fig. 1) two coaxial piezoceramic cylindrical shells of the same length, but different diameters, the space between which is filled with a liquid medium. The inner space of the shell of a smaller diameter can be evacuated, filled with gas or liquid medium. Each of the shells of the device is electrically excited by its own electronic generator with controlled amplitude and phase. It is this excitation that provides the current possibility of operational control of the dynamic properties of an acoustoelectronic device of a specific design. Moreover, each design of an acoustoelectronic device has its own set of potentially realizable dynamic capabilities that are characteristic of only it. This is due to the abundance of design parameters of the device under consideration, a change in which leads to a change in its potential dynamic properties. These parameters include: sizes of average diameters and thickness of piezoceramic shells; composition of piezoceramics; physical properties of media filling the shell. Thus, the choice of the average diameters and compositions of the piezoceramics of the shells can be used to control their resonance properties, since under radially symmetric electrical loading, the wavelength of the exciting signal in the piezoelectric material should fit along the lengths of their average circles [6]. Therefore, the considered devices can be with single-resonant excitation, when the resonant frequencies of the outer and inner shells coincide or are close [5], or two-resonance, when these resonant frequencies are different.

It is known $[7,8]$ that closed volumes of finite dimension have their own resonant frequencies due to the appearance of standing waves. The quantitative values of these frequencies are determined by the wave dimensions of the volumes and the physical characteristics of the media filling these volumes.

In work [3], the influence of the thickness of piezoceramic shells with constant filling media on the potentially possible dynamic properties of the considered acoustoelectronic device was studied.

The aim of this work is to study the potential possibilities of controlling the dynamic properties of an acoustoelectronic device with single-frequency resonant excitation of shells when the physical characteristics of the shell filling media change.

\section{STATEMENT OF THE PROBLEM. RESULTS}

Let us determine the potential for controlling the dynamic properties of a cylindrical piezoceramic acoustoelectronic device (Fig. 1) by changing the physical properties of the media filling the inner cavities of the shells. The study was performed under the following conditions:

- the average radius of the shells and the compositions of piezoelectric ceramics, which determine the same resonant frequency of the shell in vacuum, are preserved;

- the thickness of the shell does not change either;

- the conditions for operational control of the elec-

\footnotetext{
*n_bogdanova@ukr.net
} 
trical parameters of the device are accepted the same as in the works $[5,10]$.

As before $[3,5]$, the acoustoelectronic device consists of two coaxial cylindrical piezoceramic shells 1 and 2 with average radii $r_{1}$ and $r_{2}$ and thicknesses $h_{1}$ and $h_{2}$. Each of the shells has circular polarization and is formed from $M_{1}$ and $M_{2}$ rigidly glued piezoceramic segments electrically connected in parallel. On the flat faces of the segments of the first and second shells, electric voltages $\psi_{1}=\psi_{01} \cdot e^{-i \omega t}$ and $\psi_{2}=\psi_{02} \cdot e^{-i(\omega t+\varphi)}$ are applied with amplitudes $\psi_{01}$ and $\psi_{02}$, circular frequency $\omega$ and phase shift $\varphi$. The external medium I, in which the device is located, the internal medium between the shells II, and the medium inside the second shell III are characterized, respectively, by the densities $\rho_{1}, \rho_{2}, \rho_{3}$ and the speeds of sound $c_{1}, c_{2}, c_{3}$.

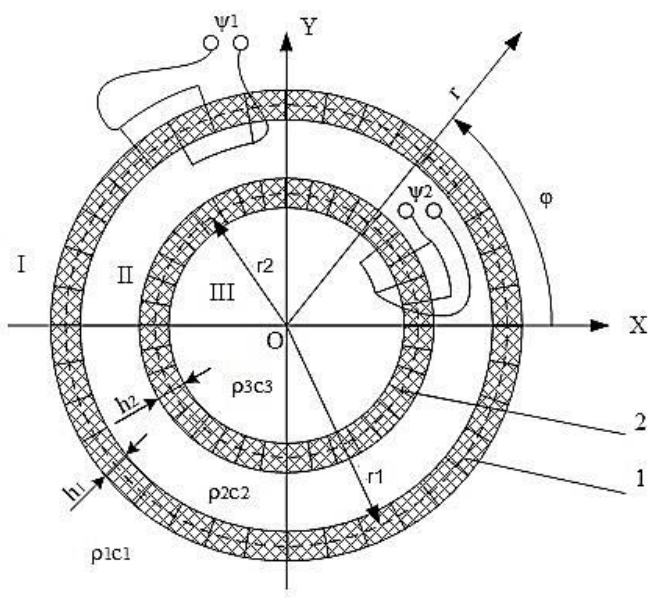

Fig. 1 - Normal cross-section of the emitter

The investigated acoustoelectronic device performs two functions: energy conversion and formation of acoustic energy in the surrounding space. The first function is characterized by the connectivity of three physical fields - electrical, mechanical, and acoustic [9]. In the process of performing the second function, a multiple process of exchange of emitted and reflected waves occurs, causing the interaction of acoustic fields created by each of the shells [3]. The presence of an acoustic field in the first function is the reason for the interconnection and processes accompanying the corresponding function. The solution to the problem of determining the analytical ratios describing the physical fields of the device, considering all types of connectivity of fields and processes, was carried out in [5]. We will use them and estimate the potential for controlling the dynamic properties of the device under consideration depending on the physical characteristics of the filling media from the frequency dependences of the pressure amplitudes in the far zone of the acoustic field of the device. As follows from [5], the expression for the acoustic pressure generated by the device in the external environment is of the form $p_{1}=\frac{i \omega \rho_{1} W_{01} H_{0}^{(1)}\left(k_{1} r\right)}{k_{1} H_{0}^{(1) \prime}\left(k_{1} r_{11}\right)}$.

The explanation of the given designations is presented in the work [5] for the far zone of the acoustic field $\left|p_{1 D}\right|=\left|p_{1}\right|$ at large values of $k_{1} r$. Note that in the rela- tions presented in [5], the physical characteristics of the media of the internal filling of the acoustoelectronic device are taken into account through the matrix elements containing the wavenumber $k_{2}$ of the system (8) (see [5]) of linear algebraic equations.

The calculations were performed for the following parameters and characteristics of the dynamically excited device: the average radii and thicknesses of the outer $(s=1)$ and inner $(s=2)$ piezoceramic shells were taken respectively equal to $r_{1}=0.096 \mathrm{~m}, h_{1}=0.006 \mathrm{~m}$ and $r_{2}=0.07 \mathrm{~m}, h_{2}=0.005 \mathrm{~m}$; the number of segments in the shells $M_{1}=M_{2}=96$; the resonant frequencies $f$ of the shells in vacuum were chosen to be the same and equal to $f=7300 \mathrm{~Hz}$, which was ensured at given average radii by choosing the compositions of piezoelectric ceramics TBK-3 (TiBaCo-3) and TsTBS-3 (ZnTiBaPb-3) [5]; water was taken as the external environment $\left(\rho_{1}=10^{3} \mathrm{~kg} / \mathrm{m}^{3} ; c_{1}=1500 \mathrm{~m} / \mathrm{s}\right)$. The space between the shells was filled with media: kerosene $\left(\rho_{2}=820 \mathrm{~kg} / \mathrm{m}^{3}\right.$; $\left.c_{2}=1295 \mathrm{~m} / \mathrm{s}\right) ; \quad$ water; glycerin $\quad\left(\rho_{2}=1200 \mathrm{~kg} / \mathrm{m}^{3}\right.$; $\left.c_{2}=1895 \mathrm{~m} / \mathrm{s}\right)$. The inner cavity of the second shell was evacuated $\left(\rho_{3}=0 ; c_{3}=0\right)$; the amplitudes of the exciting voltages were chosen equal to $\psi_{01}=200 \mathrm{~V} ; \psi_{02}=[200 \mathrm{~V}$; $120 \mathrm{~V} ; 0 \mathrm{~V}]$, with phase shifts $\varphi=[0 ; \pi]$; range of frequencies investigated $0-40 \mathrm{kHz}$.

Results of the numerical experiments are presented below (Fig. 2, Fig. 3). We define the potential dynamic properties of the device under consideration when changing the physical characteristics of its filling media. An analysis of the curves (Fig. 2, Fig. 3) shows that the frequency dependences of the pressure amplitudes for all filling media of the acoustoelectronic device have a resonant character.

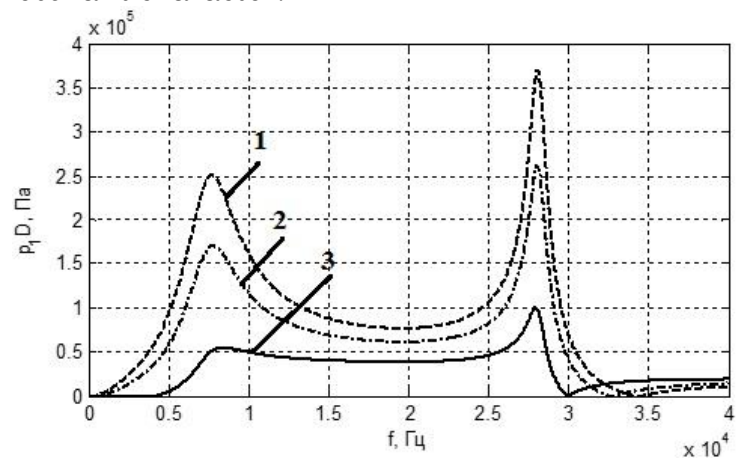

a

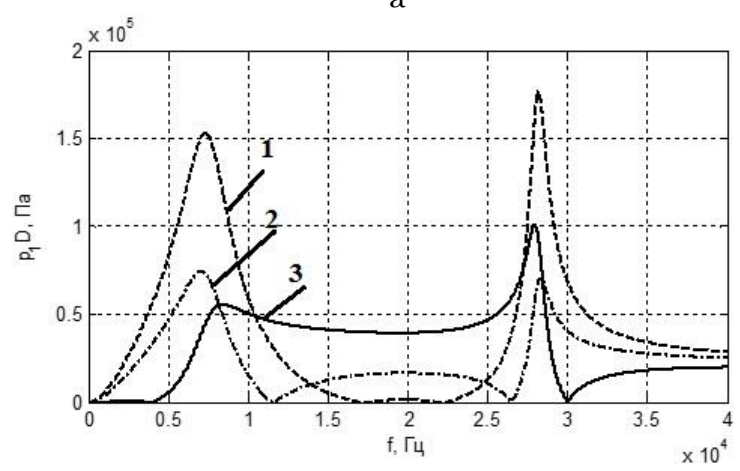

b

Fig. 2 - Frequency dependences of the acoustic pressure amplitudes of a dynamically excited acoustoelectronic device when it is filled with kerosene: $\psi_{02} / \psi_{01}=1.0$ (curve 1); $\psi_{02} / \psi_{01}=0.6$ (curve 2); $\psi_{02} / \psi_{01}=0$ (curve 3 ); $\varphi=0$ (a); $\varphi=\pi(\mathrm{b})$ 


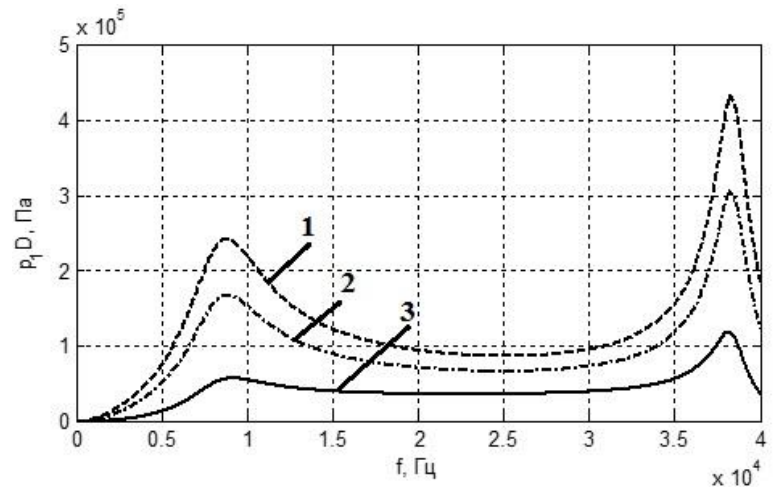

a

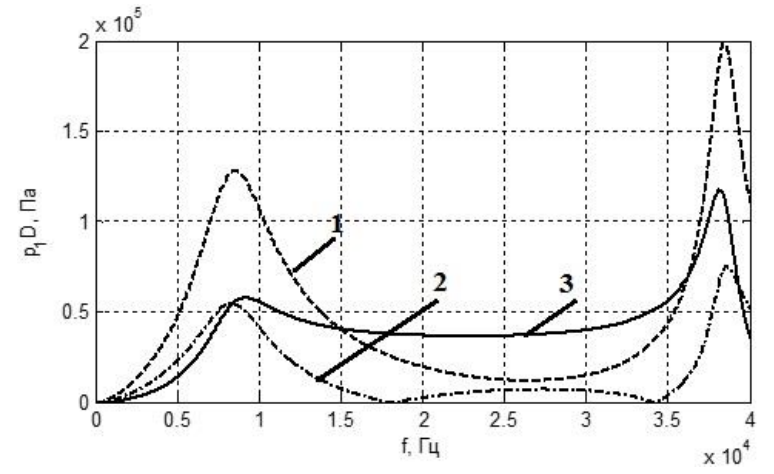

$\mathrm{b}$

Fig. 3 - Frequency dependences of the acoustic pressure amplitudes of a dynamically excited acoustoelectronic device when it is filled with glycerin: $\psi_{02} / \psi_{01}=1.0$ (curve 1); $\psi_{02} / \psi_{01}=0.6$ (curve 2); $\psi_{02} / \psi_{01}=0$ (curve 3); $\varphi=0$ (a); $\varphi=\pi(\mathrm{b})$

The reasons for this are: first, the electrical excitation of the piezoceramic shells of the device at the frequency of their mechanical resonance and, second, the resonant behavior of an elastic medium of finite dimensions in the space between the shells. It is the last physical factor that determines the appearance of the studied features in the potential dynamic properties of the device. In this case, the differences in the speeds of sound propagation in the space between the shells affect the frequency properties of the device, and the differences in the densities of these media determine the levels of pressure amplitudes at its frequencies.

An analysis of the above results indicates that, at the same or close resonant frequencies of both shells, the frequency dependences of the pressure for all the considered physical characteristics of the media filling the device are two-humped curves corresponding to two resonance regions. The first region includes the resonant frequency of the cladding and is characterized by a wide resonance band. The maximum values of the acoustic pressure in this band are close when the intershell space is filled with all the liquids under consideration, although a small advantage is observed for lighter liquids. At the same time, the values of the magnitude of the resonant frequency bands are in reverse order. Heavier filling fluids provide the dynamic device with wider resonance bands.

The frequencies themselves with the maximum values of the pressure amplitudes in the first resonance region are displaced along the frequency axis to the left as the density and speed of sound of the filling fluid decrease.
The second resonance region has its own frequency features. First, for all filling liquids, the maximum amplitudes of the pressure generated by the device in the far zone exceed those in the first resonance region by 1.6-2 times. Second, the resonance bands in the second resonance region are 1.7-3 times narrower than in the first. At the same time, the tendency established for the first resonance region to decrease the resonance bands of the device during the transition in the structure from a heavy filling liquid to a lighter one is also preserved for the second resonance region. Third, as expected, at the same distance between the surfaces of the first and second shells, replacing the filling fluid with elastic media with different speeds of sound propagation in them leads to an increase in the value of the central frequencies of the second resonance region, proportional to the ratio of the speeds of sound in the filling environments.

A significant dip in the frequency dependence of the pressure amplitudes arises between the first and second resonance regions. The length of this dip depends on the physical properties of the liquid media filling the space between the shells. The lighter the filling fluid, the smaller the frequency extent of the dip. In all cases, the minimum amplitude pressure failures were 2.5-3 times less than the maximum pressure amplitude in the first resonance region.

Thus, the analysis performed makes it possible to establish the following features characteristic of the potentially possible dynamic properties of the acoustoelectronic device under consideration when the physical characteristics of the liquid media filling its structure with single-frequency resonant excitation change. First, in all considered cases of liquid filling, two resonance regions are formed, which significantly differ from each other in the central frequencies, resonant frequency bands, and maximum pressure amplitudes in them. Second, filling the devices with liquid media lighter than water makes it possible to reduce the values of the central frequencies of the resonance regions, increase the pressure amplitudes in the resonance regions and reduce the frequency interval of the dip between them. Third, filling the devices with liquid cuts heavier than water makes it possible to increase the values of the central frequencies of the resonance regions, expand their resonance bands, increase the pressure amplitudes in the resonance regions, and increase the frequency interval of the dip between them.

We now estimate the influence of the electric operational control device with consideration of acoustoelectronic single-frequency resonant excitation at a potentially possible set of its dynamic properties. An analysis of the curves (Fig. 2, Fig. 3) shows that for all variants of the operational control of the dynamic properties of the acoustoelectronic device, its frequency properties remain resonant. In this case, with an increase in the ratio $\left|\frac{\psi_{02}}{\psi_{01}}\right|$ of exciting voltages, the levels of pressure amplitudes in both resonance regions increase, and in the region of the dip of the frequency dependence they change insignificantly. This regularity is observed for all liquid media filling the structure of the devices under consideration, and the influence of their physical 
characteristics is manifested only in the quantitative values of the pressure amplitudes.

The influence of the phase shift $\varphi$ between the excitation voltages of the first and second shells of the device is more significant. First of all, this is evident from the pressure levels in the resonance regions. Their greatest values take place with in-phase excitation of piezoceramic shells (Fig. 2a, Fig. 3a). The most unfavorable is antiphase excitation (Fig. 2b, Fig. 3b).

The established dynamic properties of an acoustoelectronic device with various filling fluids of their design have a different physical nature of their formation in the first and second resonance regions. The first region has a decisive influence function in energy conversion in piezoceramic media with its relatedness to electrical, mechanical, and acoustic fields. Taking into account that in this region the wave dimensions of the space between the first and second shells are small $\left(\frac{r_{12}-r_{21}}{\lambda} \approx 0,13\right)$, where $\lambda$ is the wavelength in the central frequency region, their effect on the radiation impedance of the shells is insignificant and depends only on the specific wave resistance $\rho_{2} c_{2}$ of the liquid media filling this space.

In the second resonance region, determining influence on the dynamic properties of the device goes to its second function - the formation of an acoustic field in the surrounding space. This formation is associated with the interaction of the shells in the acoustic field due to the superposition of multiple emitted and reflected waves of the same frequency. And since in this region the wave dimensions of the gap between the shells $\frac{r_{12}-r_{21}}{\lambda}$ are a multiple of 0.25 , a standing wave is formed in it. In this case, the radiation impedances of the shells of the acoustoelectronic device increase significantly and are almost completely determined by

\section{REFERENCES}

1. Yu.A. Koryakin, S.A. Smirnov, G.V. Yakovlev, Ship hydroacoustic equipment: state and actual problems (SPb: 2005).

2. V.T. Grinchenko, I.V. Vovk, V.T. Matsypura, Acoustics Wave Problems-Begell Hpuse (2018).

3. O. Leiko, A. Derepa, O. Pozdniakova, N. Bogdanova, 2020 IEEE 40th International Conference on Electronics and Nanotechnology (ELNANO), art. No. 19593509, 694 (Kyiv: 2020).

4. John L. Butler, Charles H. Sherman, Transducers and Arrays for Underwater Sound (Springer: New York: 2007). the wave processes in the gap [3]. Naturally, these processes depend on the speed of sound in the media filling a device.

\section{CONCLUSIONS}

It is shown that one of the approaches to controlling the potentially possible dynamic properties of an acoustoelectronic device with the same resonant excitation in the form of a coaxial system of two piezoceramic cylindrical shells with liquid filling of the intershell space is the selection of the physical characteristics of liquids. It is found that by choosing the density of a liquid and the speed of sound in it, it is easy to control the potentialities of the dynamic properties of such devices in terms of their resonance properties and amplitude-frequency characteristics. In this case, the filling of device structures with liquids lighter than water is accompanied by a decrease in the resonant frequency, a decrease in resonant frequency bands, and an increase in pressure amplitudes in the resonance regions. Filling structures with liquids heavier than water provides an increase in resonant frequencies, resonant frequency bands and pressure amplitudes in them.

The introduction into the considered devices of the operational control of their dynamic properties using the amplitudes and phases of the exciting voltages allows: first, to quantitatively change the regularities established above in the potential dynamic properties of the devices, and, second, to do this in different ways in different frequency domains.

A physical interpretation of the reasons for the formation of various features in the potentially attainable dynamic properties of the considered acoustoelectronic device in different resonance regions is given. The established features of the dynamic properties of acoustoelectronic devices of this type should be taken into account when creating technical means of acoustic sounding.

5. N.V. Bogdanova, A.G. Leiko, S.A. Naida, A.I. Drozdenko, J. Nano-Electron. Phys. 11 No 6, 06011 (2019).

6. V.S. Aronov, J. Acoust. Soc. Am. 117, 210 (2005).

7. Ultrasound: Little Encyclopedia (Chief Editor I.P. Golyamin) (Moscow: Soviet Encyclopedia, 1979)) [In Russian].

8. V.T. Grinchenko, S.V. Vovk, V.T. Matsypura, Osnovy akustiki (Kiev: Naukova dumka: 2013) [In Russian].

9. V.D. Grinchenko, A.F. Ulitko, N.A. Shul'ga, Mekhanika suyazannykh poley $v$ elementakh konstruktsiy. T.5. Elektrouprugost' (Kiev: Naukova dumka: 1989) [In Russian]. 


\title{
Про один підхід до управління динамічними властивостями циліндричного п'єзокерамічного акустоелектронного пристрою з одночастотним резонансним збудженням
}

\author{
О.Г. Лейко, Н.В. Богданова, О.В. Богданов, А.О. Лейко, О.В. Гармаш
}

Національний технічний університет Украӥни "Київський політехнічний інститут ілені I. Сікорського» вул. Політехнічна, 16, 03056 Київ, Україна

\begin{abstract}
Досліджено потенційно досяжні динамічні властивості акустоелектронного пристрою з одночастотним резонансним збудженням у вигляді коаксіальної системи, утвореної з двох циліндричних п'єзокерамічних оболонок і шару рідини між ними, в залежності від фізичних характеристик ціеї рідини. Методом чисельного аналізу, на прикладі акустичних полів, встановлені особливості поведінки потенційно можливих динамічних властивостей таких пристроїв для варіантів їх побудови з заповненням рідинами з різною густиною і швидкістю звуку в них. Досліджені особливості впливу фізичних характеристик рідин, які заповнюють пристрій, на потенційно можливі динамічні властивості акустоелект ронних пристроїв такого типу. Показано, що ці особливості полягають у формуванні двох резонансних областей, які значно відрізняються між собою по центральним частотам, смугами резонансних частот максимальними амплітудами тиску в них. Заповнення пристроїв легкими рідинами обумовлюе зменшення значень центральних частот резонансних областей та частотного інтервалу малих амплітуд тиску між двома резонансними областями. Заповнення пристроїв важкими рідинами характеризуеться протилежною дією. Проаналізовано вплив на встановлені потенційно можливі динамічні властивості таких пристроїв шляхом введення в них оперативних методів управління з електричної сторони. Викладено фізичні причини виникнення встановлених динамічних властивостей.
\end{abstract}

Ключові слова: Акустоелектронний пристрій, Одночастотне резонансне збудження, Потенційно можливі динамічні властивості, Заповнюючі рідини. 